\title{
PERAN ETIKA KERJA DAN MOTIVASI KERJA ISLAMI BAGI KINERJA KARYAWAN PT. SUN LIFE FINANCIAL SYARIAH CABANG TANGERANG
}

\author{
Oom Komariyah ${ }^{1}$ \\ Rizki Pawzi Sukart ${ }^{2}$ \\ ${ }^{1,2}$ Sekolah Tinggi Ekonomi Syariah Islamic Village Tangerang \\ Email: komariahrahmat@yahoo.com, Rizkipawzi78@gmail.com
}

\begin{abstract}
The purpose of this study is to examine the effect of work ethics and Islamic motivation work on performance of the employees in PT. Sun Life Financial Syariah Tangerang-Banten. The sampling technique in this research uses purposive sampling method and to determine the number of respondents Slovin formula is used, Based on this formula the samples taken are 52 employees. This study is a quantitative descriptive method by using multiple regression method for analyzing the data and for data collection questionnaire is used in this research. The findings of this study is there is an positive impact of ethics work ethic and Islamic motivation work on employee performance at PT. Sun Life Financial Syariah, this can be explained through the coefficient of determination test of 50.25\%. Simultaneous Test $(F)$ and Partial Test $(t)$ results show that work ethics $(X 1)$ and Islamic motivation work (X2) have a positive and significant effect on performance of employee $(Y)$, where when Islamic work ethics increase at 1\%, employee performance will increase amounted to $0.42 \%$ and when Islamic work motivation is increased by $1 \%$ then employee performance increases by $0.47 \%$.
\end{abstract}

Keywords :Islamic Work Ethics, Islamic Work Motivation, Employee Performance.

\section{PENDAHULUAN}

Perkembangan asuransi syariah di Indonesia terus memberikan hal yang positif, seiring dengan perkembangan industri keuangan syariah pada umumnya. Asuransi syariah di Indonesia telah ada sejak tahun 1994 dengan berdirinya perusahaan asuransi Takaful Indonesia (Effendi, 2016, p. 73), minat masyarakat yang tinggi terhadap asuransi syariah telah mencerminkan pangsa pasar yang besar dalam industri syariah di Indonesia, hal inipun tak lepas dari ketentuan regulasi yang menjamin hukum kegiatan asuransi syariah (Ramadhani, 2015, p.57-58). Salah satu lembaga asuransi syariah yang ada di kota Tangerang yaitu PT. Sunlife Financial Syariah merupakan lembaga keuangan asuransi yang meraih penghargaan "The Best Risk Management Islamic Life Insurance 2014" dan " Top 2 Asuransi Jiwa Katagori Asset Rp. 5-15 Triliun " dari Warta Ekonomi dalam ajang Insurance Consumer Choice Awards 2015. Penghargaan yang didapatkan PT. Sunlife Financial Syariah tidak luput dari peranan sumber daya manusia dengan berkomitmen untuk memberikan layanan asuransi syariah yang terbaik bagi seluruh masyarakat Indonesia (Sun Life Syariah, http://www.sunlifesyariah.com). PT. Sunlife Financial Syariah dalam menjalankan komitmennya memerlukan sumber daya manusia yang Islami dan berkualitas dalam memberikan pelayanan kepada masyarakat bukan hanya pengetahuan tentang produk, akan tetapi etika Islam dalam bekerja juga diperlukan karena sumber daya manusia yang berkualitas akan mampu mempengaruhi rasa optimisme dan kepercayaan pada perkembangan industri keuangan syariah di masa depan (Ramadhani, 2015, p. 75). Adapun faktor lain yang dibutuhkan karyawan untuk memberikan kontribusi dalam mancapai target kerjanya, yaitu memberikan motivasi kerja Islam kepada karyawan. Secara umum motivasi merupakan suatu keinginan dan dorongan di dalam diri pegawai untuk melaksanakan tugas dan tanggung jawabnya dengan baik (Darmadi, 2018, p. 294).Maka etika kerja Islam dan motivasi kerja Islam sangat dibutuhkan untuk meningkatkan kinerja karyawan pada perusahaan asuransi syariah.

Berdasarkan latar belakang diatas, maka penulis tertarik untuk melakukan sebuah penelitian.Adapun yang menjadi judul dalam penelitian ini yaitu "Pengaruh Etika Kerja dan Motivasi Kerja Islam Terhadap Kinerja Karyawan Pada PT. Sun Life Financial Syariah 
Cabang Tangerang - Banten".Adapun dalam penelitian ini penulis mempunyai tujuan penelitian yaitu Untuk mengetahui pengaruh etika kerja Islam dan motivasi kerja Islam terhadap kinerja karyawan pada PT. Sun Life Financial Syariah Cabang Tangerang - Banten.

\section{Asuransi}

\section{KAJIAN LITERATUR}

Asuransi menurut UU No. 40 tahun 2014 tentang perasuransi bahwa asuransi merupakan perjanjian antara dua pihak, yaitu perusahaan asuransi dan pemegang polis (nasabah), yang menjadi dasar bagi penerimaan premi oleh perusahaan asuransi sebagai imbalan.

Menurut Fatwa Dewan Syariah Nasional, Asuransi syariah (ta'min, takaful, atau tadhamun) adalah usaha saling melindungi dan tolong-menolong di antara sejumlah orang/pihak melalui investasi dalam bentuk aset dan/atau tabarru' yang memberikan pola pengembalian untuk menghadapi resiko tertentu melalui akad (perikatan) yang sesuai dengan syariah (Fatwa DSN MUI tahun 2001, 2018. p. $5)$.

Sedangkan asuransi menurut ahli (Wirjono Prodjodikoro, (1987) yaitu suatu perjanjian pihak yang menjamin berjanji kepada pihak yang dijamin, untuk menerima sejumlah uang premi sebagai pengganti kerugian, yang mungkin akan diderita oleh yang dijamin, karena akibat dari suatu peristiwa yang belum jelas.

\section{Etika Kerja Islam}

Etika kerja Islam adalah konsep etika yang didasarkan pada ajaran dan prinsip Islam yang bersandar pada keyakinan.Sementara itu, komitmen organisasi terkait dengan keterikatan dan perilaku karyawan terhadap organisasi.Model struktural adalah dibangun untuk menguji efek etika kerja Islam pada komitmen organisasi (Salahudin Dkk, 2016, p. 582).berikut adalah karakteristik etika bekerja yang ada dalam Islam yaitu (Purkon, 2014, p. 40-42) :

a. Niat Ikhlas karena Allah SWT dalam bekerja.

b. Itqon dalam bekerja.

c. Profesional dan Bertanggung Jawab.

d. Jujur dan Amanah.

e. Menjaga Akhlak sebagai Seorang Muslim.

f. Berbuat Baik dalam Segala Hal.

\section{Motivasi Kerja Islam}

Motivasi kerja Islam adalah salah satu kewajiban beribadah kepada Allah SWT setelah ibadah fardhu lainya karena motivasi kerja Islam bukan hanya untuk mencari dan memenuhi nafkah semata. Motivasi kerja Islam adalah suatu komitmen yang terkait antara sebuah kepercayaan terhadap Allah SWT dengan seseorang dalam menjalankan pekerjaanya, banyak orang yang hanya selalu bekerja demi kepentingan materi saja tak sedikitpun mementingkan akhirat belaka maka dari itu sebaiknya para pekerja perlu memiliki suatu motivasi yang baik dan dibenarkan oleh Islam (Anoraga dan Prasetyo, 2015, p. 533-534).

\section{Kinerja Karyawan}

Kinerja adalah suatu titik akhir seseorang, sumber daya dan lingkungan tertentu yang dikumpulkan secara bersama dengan memiliki maksud untuk menghasilkan hal-hal tertentu, baik itu suatu produk yang tak kasat mata ataupun jasa. Kaitanya kinerja karyawan adalah selama interaksi tersebut memberikan hasil dalam tingkatan dan sebuah prestasi yang sesuai tujuan perusahaan dengan level biaya yang telah disepakati sebelumnya maka kinerja yang dihasilkan akan dinilai memuaskan begitupun sebaliknya ketika hasil itu mengecewakan maka kinerja tersebut dinilai buruk ataupun merosot. Dengan begitu, kinerja secara tidak langsung telah menitikberatkan pada seorang pegawai atau karyawan dengan hasil atau keluaran (outcome) dari sebuah pekerjaan dalam suatu organisasi (Fattah, 2017, p. 9). 


\section{KERANGKA PEMIKIRAN}

Untuk mengetahui masalah dari penelitian yang akan di bahas. Maka diperlukan adanya kerangka pemikiran yang dijadikan sebagai landasan penelitian ini yaitu :

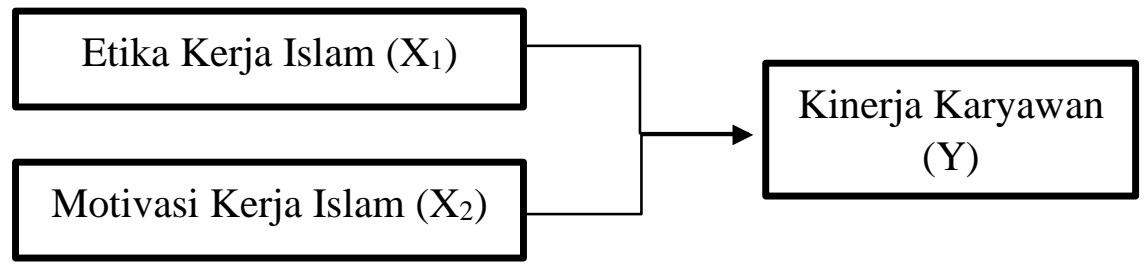

Gambar 2.1

Kerangka Pemikiran

\section{Hipotesis Penelitian}

Hipotesis merupakan jawaban sementara terhadap rumusan masalah penelitian dimana rumusan masalah penelitian telah dinyatakan dalam bentuk pertanyaan.Hipotesis juga dikatakan sementara karena jawaban yang diberikan baru didasarkan pada teori. Hipotesis dalam penulisan ini yaitu:

Ha: Diduga sementara adanya pengaruh positif etika kerja Islam dan motivasi kerja Islam terhadap kinerja karyawan.

\section{METODOLOGI PENELITIAN}

Metode yang digunakan dalam penelitian ini adalah metode kuantitaif yaitu metode yang menggambarkan suatu kondisi apa adanya dengan menggunakan data berupa angka sebagai alat untuk menganalisa keterangan mengenai apa yang akan diketahui. Metode kuantitatif ditujukan untuk mengetahui hubungan suatu variabel dengan variabel lainya, yang dinyatakan dengan besarnya koefisien korelasi dan keberartian secara signifikan secara statistik (Hamdi dan Bahruddin, 2015, p. 2$5)$.

Dengan teknik sampling Purposive Sampling yaitu pengambilan sample berdasarkan pertimbangan tertentu sehingga sample hanya representatif untuk populasi yang diteliti (Arifin, 2017, p. 10). Sampel yang diperoleh sebanyak 52 responden. Untuk mengetahui pengaruh etika kerja dan motivasi kerja Islam terhadap kinerja karyawan pada PT. Sun Life Financial Syariah, maka analisis data yang digunakan dalam penelitian ini yaitu :

\section{Pengujian Instrumen Penelitian}

\section{Uji Validitas}

Validitas dapat diartikan sebagai suatu ukuran yang menunjukkan tingkat-tingkat kevalidan dan kesahihan suatu instrument (Mulyono, 2015, p. 84).

\section{Uji Reliabilitas}

Merupakan ukuran yang menunjukkan bahwa alat ukur yang digunakan dalam penelitian keperilakuan mempunyai keandalan sebagai alat ukur, menggunakan rumus Cronbach Alpha dengan kriteria uji jika Cronbach Alpha> 0,6 maka instrumen tersebut reliabilitas (Hamdi dan Bahruddin, 2015, p.84).

\section{Analisis Deskriptif}

Yaitu data yang menggambarkan berbagai karakteristik data yang berasal dari sampel yang terdiri dari mean, median, modus, presentil, desil, quartile (Sujarweni, 2014, p. 105). 


\section{Uji Asumsi Klasik}

Uji asumsi klasik dalam penelitian ini dilakukan untuk menilai kehandalan model yang terdiri dari uji normalitas, uji multikolonearitas dan uji heteroskedastisitas (Hamdi dan Bahruddin, 2015, p. $110)$.

\section{Analisis Regresi Linier Berganda}

Adalah perluasan dari regresi linier sederhana dengan dua atau lebih variabel bebas yang digunakan sebagai predictor dan satu variabel tergantung yang diprediksi (Jonathan, 2014, p. 189).

\section{Uji Hipotesis}

Pengujian hipotesis dilakukan untuk membantu dalam pengambilan keputusan suatu hipotesis yang diajukan (Arifin, 2017, p. 63).

1. Uji-F (Simultan)

Kepercayaan yang digunakan adalah 0,05 . Apabila nilai $\mathrm{F}$ hasil perhitungan lebih besar dari pada nilai $\mathrm{F}$ menurut tabel maka hipotesis alternatif, yang menyatakan bahwa variabel etika kerja Islam dan motivasi kerja Islam secara simultan berpengaruh signifikan terhadap variabel kinerja karyawan.

H0 diterima, bila Fhitung $\leq$ Ftabel atau nilai sig $>0,05$

H0 ditolak, bila Fhitung $\geq$ Ftabel atau nilai sig $<0,05$

2. Uji-t (Parsial)

Dilakukan untuk mengetahui pengaruh nyata atau tidak secara parsial variabel-variabel independen terhadap variabel dependen. Derajat signifikansi yang digunakan adalah 0,05. Apabila nilai signifikan lebih kecil dari derajat kepercayaan maka kita menerima hipotesis alternative, yang menyatakan bahwa variabel etika kerja Islam dan motivasi kerja Islam secara parsial mempengaruhi variabel kinerja karyawan (Mulyono, 2018, p.113).

3. Uji Koefisien Determinasi (R2)

Digunakan untuk mengukur seberapa besar kemampuan pengaruh variabel bebas dapat menjelaskan variabel terikat. Semakin besar nilai koefisien determinasi, maka semakin baik kemampuan varian dan variabel bebas menerangkan variabel terkait (Hantono, 2018, p. 71).

\section{Hasil Penelitian}

\section{HASIL DAN PEMBAHASAN}

1. Instrumen Penelitian

a. Uji Validitas

Hasil uji validitas menunjukkan bahwa seluruh butir pertanyaan variabel dalam kuesioner ini dinyatakan valid. Artinya seluruh butir pertanyaan variabel sesuai dengan apa yang akan diukur dalam penelitian ini.

b. Uji Reliabilitas

Hasil uji reliabilitas menunjukkan bahwa butir pertanyaan dalam kuesioner penelitian dengan jumlah 52 responden tersebut dinyatakan reliabel karena mempunyai nilai Cronbach's Alpha lebih dari 0,60.

\section{Analisis Deskriptif}

Hasil uji deskriptif Variabel Kinerja Karyawan (Y) menjelaskan bahwa jawaban nilai rata-rata dari hasil 52 responden sebesar 38,73 yang artinya rata-rata responden menjawab pilihan setuju (S) dan sangat setuju (SS) atas pertanyaan variabel kinerja karyawan. Variabel Etika Kerja (X1) menjelaskan bahwa jawaban nilai rata-rata dari hasil 52 responden sebesar 48,71 yang artinya ratarata responden menjawab pilihan setuju (S) dan sangat setuju (SS) atas pertanyaan variabel etika kerja Islam. Variabel Motivasi Kerja (X2) menjelaskan bahwa jawaban nilai rata-rata dari hasil 52 responden sebesar 27,48 yang artinya rata-rata responden menjawab pilihan setuju (S) dan sangat setuju (SS) atas pertanyaan variabel motivasi kerja Islam. 
Hasil dari keseluruhan uji asumsi klasik diantaranya uji normalitas, multikolinearitas, dan heteroskedastisitas menunjukkan bahwa relatif normal serta tidak terjadi multikolinearitas dan heteroskedastisitas.

4. Regresi Linear Berganda

Tabel 4.1

Hasil Analisis Regresi Linear Berganda

\begin{tabular}{|c|c|c|c|c|c|c|c|}
\hline \multicolumn{8}{|c|}{ Coefficients $^{a}$} \\
\hline \multirow[b]{2}{*}{ Model } & \multicolumn{2}{|c|}{$\begin{array}{l}\text { Unstandardized } \\
\text { Coefficients }\end{array}$} & \multirow{2}{*}{$\begin{array}{l}\text { Standardiz } \\
\text { ed } \\
\text { Coefficien } \\
\text { ts } \\
\text { Beta } \\
\end{array}$} & \multirow[b]{2}{*}{$\mathrm{t}$} & \multirow[b]{2}{*}{ Sig. } & \multicolumn{2}{|c|}{$\begin{array}{l}\text { Collinearity } \\
\text { Statistics }\end{array}$} \\
\hline & B & \begin{tabular}{|l} 
Std. \\
Error
\end{tabular} & & & & $\begin{array}{l}\text { Toleran } \\
\text { ce }\end{array}$ & VIF \\
\hline (Constant) & 5,168 & 4,579 & & $\begin{array}{l}1,12 \\
9\end{array}$ &, 265 & & \\
\hline E_KERJA & ,423 &, 120 &, 471 & $\begin{array}{l}3,52 \\
8\end{array}$ &, 001 & ,543 & $\begin{array}{l}1,84 \\
2\end{array}$ \\
\hline M_KERJA &, 472 &, 199 &, 317 & $\begin{array}{l}2,37 \\
2\end{array}$ &, 022 &, 543 & $\begin{array}{l}1,84 \\
2\end{array}$ \\
\hline
\end{tabular}

a. Dependent Variable: K_KARYAWAN

Sumber : Data Primer Diolah Oleh SPSS 22, 2019

Berdasarkan tabel diatas dapat diperoleh hasil persamaan regresi yaitu :

$$
\mathrm{Y}=5,168+0,423 \mathrm{X} 1+0,472 \mathrm{X} 2
$$

Konstanta (a) sebesar 5,168 yang artinya bahwa Y (kinerja karyawan) akan bernilai 5,168 jika semua variabel independen (etika kerja Islam dan motivasi kerja Islam) masing-masing memiliki nilai 0. Apabila nilai etika kerja Islam dan nilai motivasi kerja Islam ditingkatkan $1 \%$ maka akan meningkatkan kinerja karyawan naik sebesar $0,42 \%$ dan meningkatkan kinerja karyawan naik sebesar $0,47 \%$.

5. Hasil Uji Hipotesis

a. Uji F (Simultan)

Tabel 4.2

Hasil Uji-F (Simultan)

ANOVA

\begin{tabular}{|ll|l|l|l|l|l|}
\hline \multicolumn{2}{|l|}{ Model } & $\begin{array}{l}\text { Sum of } \\
\text { Squares }\end{array}$ & df & $\begin{array}{l}\text { Mean } \\
\text { Square }\end{array}$ & F & Sig. \\
\hline 1 & $\begin{array}{l}\text { Regressi } \\
\text { on }\end{array}$ & 425,262 & 2 & 212,631 & $\begin{array}{l}27,06 \\
4\end{array}$ &, $000^{\mathrm{b}}$ \\
& $\begin{array}{l}\text { Residual } \\
\text { Total }\end{array}$ & 384,968 & 49 & 7,856 & & \\
\hline
\end{tabular}

a. Dependent Variable: K_KARYAWAN

b. Predictors: (Constant), M_KERJA, E_KERJA

Sumber : Data Primer Diolah Oleh SPSS 22, 2019

Dari Tabel 4.12 dapat dijelaskan bahwa Fhitung yaitu sebesar 27,064 dengan signifikasi 0,000 $<0,05$,Sehingga dapat disimpulkan bahwa terdapat pengaruh antara etika kerja dan motivasi kerja Islam terhadap kinerja karyawan.

b. Uji T (Parsial) 
Tabel 4.3

Hasil Uji-T (Parsial)

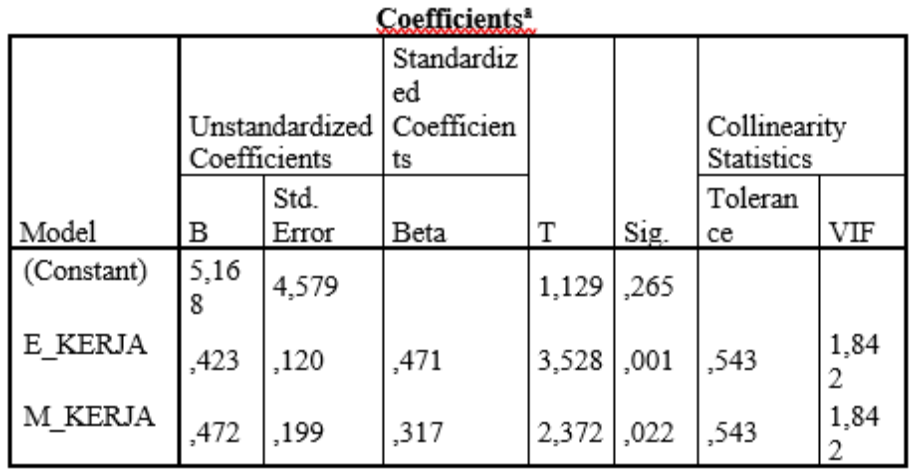

a. Dependent Variable: K_KARYAWAN

Sumber : Data Primer Diolah Oleh SPSS 22, 2019

c. Uji Koefisien Determinasi (R2)

Tabel 4.8

Hasil Koefisien Determinasi (R2)

Model Summary

\begin{tabular}{|l|l|l|l|l|}
\hline Model & $\mathrm{R}$ & R Square & $\begin{array}{l}\text { Adjusted } \\
\text { Square }\end{array}$ & $\begin{array}{l}\text { Std. Error of the } \\
\text { Estimate }\end{array}$ \\
\hline 1 &, $724^{\mathrm{a}}$ &, 525 &, 505 & 2,80294 \\
\hline
\end{tabular}

a. Predictors: (Constant), M KERJA, E KERJA

Sumber : Data Primer Diolah Oleh SPSS 22, 2019

\section{HASIL DAN PEMBAHASAN}

\section{Pengaruh Etika Kerja Islam Terhadap Kinerja Karyawan}

Hasil uji t (partial) variabel etika kerja Islam menunjukan nilai $t_{\text {hitung }}$ positif sebesar 3,528 $>t_{\text {tabel }}$ 2,009 dan nilai signifikansi sebesar 0,001 < 0,05. Maka hasilnya H0 ditolak dan H1 diterima, yang berarti bahwa etika kerja Islam (X1) berpengaruh positif dan signifikan terhadap kinerja karyawan. Berdasarkan hasil uji statistik maka dapat jelaskan bahwa etika kerja Islam berpengaruh positif dan signifikan terhadap kinerja karyawan, artinya sebuah etika kerja yang baik akan mempengaruhi kinerja karyawan secara signifikan. Hasil ini diperkuat dengan penelitian terdahulu oleh $\mathrm{M}$. Kurniawan (2017) dan Afiatun Nadipah (2016) yang juga menyatakan bahwa etika kerja Islam berpengaruh terhadap kinerja karyawan.

\section{Pengaruh Motivasi Kerja Islam Terhadap Kinerja Karyawan}

Hasil uji $\mathrm{t}$ (parsial) variabel motivasi kerja Islam menunjukan nilai $t_{\text {hitung }}$ positif sebesar 2,372 > $t_{\text {tabel }}$ 2,009 dan nilai signifikansi sebesar 0,022 <0,05. Maka hasilnya H0 ditolak dan H1 diterima, yang berarti bahwa motivasi kerja Islam (X2) berpengaruh positif dan signifikan terhadap kinerja karyawan. Berdasarkan hasil uji statistik, dapat dijelaskan bahwa motivasi kerja Islam berpengaruh positif dan signifikan terhadap kinerja karyawan, artinya sebuah motivasi kerja yang kuat dalam diri seseorang akan mempengaruhi kinerja karyawan secara signifikan. Hasil ini diperkuat dengan penelitian terdahulu oleh Zumrotul Muhzinat (2018), M. Kurniawan (2017) dan Afiatun Nadipah (2016) yang juga menyatakan bahwa motivasi kerja Islam berpengaruh terhadap kinerja karyawan.

\section{Pengaruh Etika Kerja dan Motivasi Kerja Islam terhadap Kinerja Karyawan}

Hasil uji f (simultan) menunjukan bahwa terdapat pengaruh yang positif dan signifikan antara etika kerja dan motivasi kerja Islam terhadap kinerja karyawan. Hal tersebut diperkuat dengan hasil analisis linear berganda yang menyatakan apabila nilai etika kerja Islam ditingkatkan $1 \%$ maka akan meningkatkan kinerja karyawan naik sebesar $0,42 \%$. dan apabila nilai motivasi kerja Islam ditingkatkan $1 \%$ maka akan meningkatkan kinerja karyawan naik sebesar $0,47 \%$.

\section{KESIMPULAN}

Tersedia online : http://jurnal.stesislamicvillage.ac.id/index.php/JURNAL 
Berdasarkan analisis penelitian, mengenai etika kerja dan motivasi kerja Islam terhadap kinerja karyawan pada PT. Sun Life Financial Syariah Cabang Tangerang, maka dapat disimpulkan etika kerja Islam dan motivasi kerja Islam berpengaruh positif dan signifikan terhadap kinerja karyawan pada PT. Sun Life Financial Syariah Cabang Tangerang. Secara bersama-sama etika kerja dan motivasi kerja Islam berpengaruh positif dan signifikan terhadap kinerja karyawan, dimana ketika etika kerja Islam ditingkatkan $1 \%$ maka kinerja karyawan akan meningkat sebesar $0,42 \%$ dan ketika motivasi kerja Islam ditingkatkan $1 \%$ maka kinerja karyawan akan meningkat sebesar $0,47 \%$.

\section{IMPLIKASI}

Berdasarkan hasil penelitian tersebut dikemukakan implikasi secara teoritis dan praktis yaitu :

1. Secara Teoritis

Etika kerja dan motivasi kerja Islam yang baik sesuai prinsip Islam dapat mempengaruhi karyawan pada PT. Sun Life Financial Syariah Cabang Tangerang - Banten.

2. Secara Praktis

Hasil penelitian ini dapat dijadikan sebagai masukan bagi perusahaan PT. Sun Life Financial Syariah untuk lebih meningkatkan kinerja karyawan dalam segi etika kerja Islam dan motivasi kerja Islam.

\section{SARAN}

Berdasarkan hasil penelitian dan kesimpulan diatas, maka peneliti akan mencoba menyampaikan saran-saran yang diharapkan dapat bermanfaat untuk semua pihak. Saran-saran tersebut diantaranya :

\section{Bagi PT. Sun Life Financial Syariah}

Diharapkan dengan adanya penelitian ini dapat dijadikan bahan masukan ataupun sebagai bahan pertimbangan untuk lebih meningkatkan kinerja karyawan sehingga mampu meningkatkan provit dan selalu berinovasi dalam pasar syariah agar mampu bersaing dipasar asuransi syariah internasional tentu tak luput sesuai syariat Islam.

\section{Bagi Karyawan}

Diharapkan penelitian ini dapat menambah wawasan dan kesadaran terkait etika kerja Islam dengan menjadikanya sebagai pondasi diri dalam bekerja karena seseorang yang memiliki etika kerja Islam yang tinggi akan selalu mematuhi dan taat terhadap peraturan yang berlaku serta sanggup menjalankan dan tidak menolak untuk menerima sanksi yang diterimanya sehingga akan berimplikasi terhadap kinerja karyawan yang semakin meningkat, kemudian dengan menumbuhkan motivasi kerja Islam dalam diri setiap karyawan akan menumbuhkan semangat dalam bekerja dan berupaya untuk melakukan semaksimal mungkin pekerjaan yang mereka lakukan dengan tujuan agar kepentingan di dunia ataupun di akhirat dapat terpenuhi sehingga mampu meningkatkan kinerja karyawan.

\section{Bagi Akademisi}

Bagi penelitian akademisi, diharapkan penelitian selanjutnya dapat menggunakan penelitian ini sebagai informasi serta dapat digunakan sebagai landasan dalam tema yang sama dan sebagai tambahan ilmu bagi peneliti, selanjutnya disarankan untuk menambah variabel independen lainya serta didukung oleh teori-teori pada riset sebelumnya.

\section{DAFTAR PUSTAKA}

Anoraga, Bhirawa, dan Ari Prasetyo. "Motivasi Kerja Islam dan Etos Kerja Islam Karyawan Bank Jatim Syariah Cab.Surabaya” Vol. 2 No.7 (Juli 2015).

Arifin, Johar. SPSS 24 untuk Penelitian dan Skripsi.Elex Media Komputindo, 2017.

Arip Purkon, Kerja Berbuah Surga (Gramedia Pustaka Utama, 2014), h.37-42.

Asep Saepul Hamdi dan E. Bahruddin, Metode Penelitian Kuantitatif Aplikasi dalam Pendidikan. Deepublish, 2015.

Prodjokoro, Wirjono "Hukum Asuransi di Indonesia", Jakarta 1987 
Darmadi.Manajemen Sumber Daya Manusia Kekepalasekolahan "Melejitkan Produktivitas Kerja Kepala Sekolah dan Faktor-Faktor yang Memengaruhi. 'Deepublish, 2018.

Dr. H. A. Hussein Fattah,M.M."Kepuasan Kerja dan Kinerja Pegawai", (Elmatera, Anggota IKAPI, 2017), 8-14.

Effendi, Afif. "Asuransi Syariah Di Indonesia (Studi Tentang Peluang ke Depan Industri Asuransi Syariah).” Wahana Akademika: Jurnal Studi Islam dan Sosial 3, No. 2 (28 Desember 2016), h.73-74

Fatwa Dewan Sariah Nasional,(Majelis Ulama IndonesiaTahun 2001),"Tentang Pedoman Umum Asuransi Syariah"

http://www.sunlife-syariah.com/ "Pedoman Umum Asuransi Syariah | Sun Life Syariah," (diakses 10 Desember 2018).

Mulyono, Berprestasi Melalui JFP Ayo Kumpulkan Angka Kreditmu (Deepublish, 2018).

Sufren Natanael Yonathan, "Belajar Otodidak SPSS Pasti Bisa" (Elex Media Komputindo, 2014), h.65.

Sujarweni, "Metodologi Penelitian" (Pustakabarupress, 2014).

Salahudin Dkk "The Effect of Islamic Work Ethics on Organizational Commitment" ScienceDirect, Journal Economic and Finance (2016), h.582-583.

Ramadhani, "Prospek dan tantangan Perkembangan Asuransi Syariah di Indonesia," Vol 01, No.1 (Desember 2015), h. 57-58.

Undang-Undang Republik Indonesia "No. 40 Tahun 2014 tentang Perasuransian". 